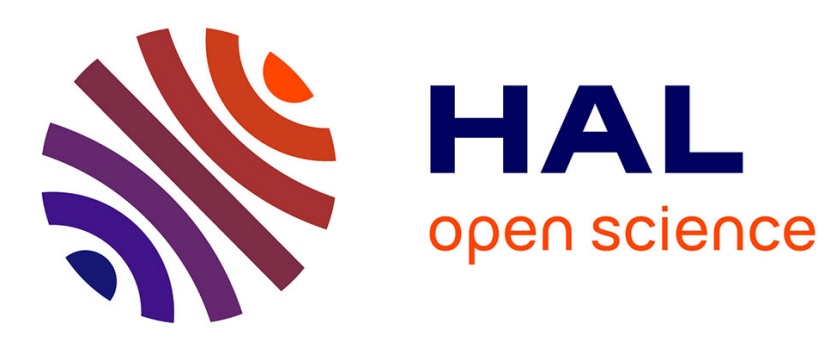

\title{
Natural occurrence of fumonisin B2 in red wine from Italy
}

\author{
Antonio Logrieco, Lia Ferracane, Angelo Visconti, Alberto Ritieni
}

\section{To cite this version:}

Antonio Logrieco, Lia Ferracane, Angelo Visconti, Alberto Ritieni. Natural occurrence of fumonisin B2 in red wine from Italy. Food Additives and Contaminants, 2010, 27 (08), pp.1136-1141. 10.1080/19440041003716547 . hal-00604047

\section{HAL Id: hal-00604047 https://hal.science/hal-00604047}

Submitted on 28 Jun 2011

HAL is a multi-disciplinary open access archive for the deposit and dissemination of scientific research documents, whether they are published or not. The documents may come from teaching and research institutions in France or abroad, or from public or private research centers.
L'archive ouverte pluridisciplinaire HAL, est destinée au dépôt et à la diffusion de documents scientifiques de niveau recherche, publiés ou non, émanant des établissements d'enseignement et de recherche français ou étrangers, des laboratoires publics ou privés. 


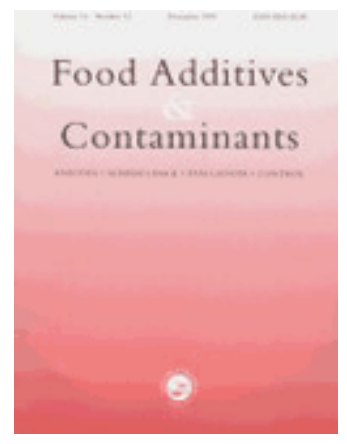

\section{Natural occurrence of fumonisin B2 in red wine from Italy}

\begin{tabular}{|r|l|}
\hline Journal: & Food Additives and Contaminants \\
\hline Manuscript ID: & TFAC-2010-019.R1 \\
\hline Manuscript Type: & Original Research Paper \\
\hline Methods/Techniques: & Exposure, LC/MS, Survey \\
\hline Additives/Contaminants: & Fumonisins, Mycotoxins \\
\hline Food Types: & Wine \\
\hline
\end{tabular}

SCHOLARONE ${ }^{\mathrm{m}}$ Manuscripts 
3 Short title: Fumonisin $B_{2}$ in wine

4

\section{Natural occurrence of fumonisin $B_{2}$ in red wine from Italy}

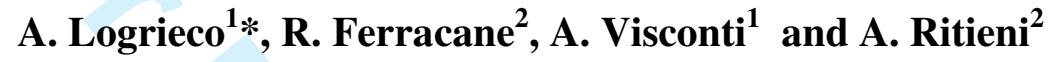

9

$10{ }^{1}$ Institute of Sciences of Food Production, CNR, Via Amendola 122/O, 70126, Bari, Italy and

11 2Dipartimento di Scienza degli Alimenti, Università degli Studi di Napoli "Federico II", via

16 *Correspondence: Antonio Logrieco. E-mail antonio.logrieco@ispa.cnr.it 
$2 \quad$ Abstract

3 The potential risk of exposure to fumonisin $\mathrm{B}_{2}\left(\mathrm{FB}_{2}\right)$ in the grape-wine chain has been 4 recently pointed out after reporting Aspergillus niger in grapes and its ability to produce $5 \quad \mathrm{FB}_{2}$ and $\mathrm{FB}_{4}$. The occurrence of these two fumonisins in wine was investigated by 6 LC/MS/MS in fifty-one market samples (45 red, 5 white and one rosè wine) produced in 7 various Italian regions. Nine samples of red wine were found contaminated by fumonisin $\mathrm{B}_{2}$ 8 at levels ranging from 0.4 to $2.4 \mathrm{ng} / \mathrm{mL}$, while $\mathrm{FB}_{4}$ was not detected in any of the tested 9 samples. This is the first report on the natural occurrence of $\mathrm{FB}_{2}$ in wine indicating that, 10 although al low levels, there is a potential risk of $\mathrm{FB}_{2}$ exposure for the wine-consumer.

12 Keywords: Fumonisins; Aspergillus species; wine; mycotoxins; food safety 


\section{Introduction}

Grapes and derived products such as grape juices and wines have been reported as potentially contaminated with ochratoxin A (Zimmerli and Dick 1996; Visconti et al. 1999). "Black aspergilli", mainly Aspergillus carbonarius followed by A. niger and A. tubingensis, are the main source of contamination by ochratoxin A of grapes and wines (Abarca et al. 2001; Battilani et al. 2003; Belli et al. 2004; Perrone et al. 2006). Ochratoxin A has been shown to be nephrotoxic, immunotoxic and teratogenic to several species of animals and to cause kidney and liver tumours in mice and rats (WHO, 2001).

Recently, some industrially important strains of A. niger were reported to produce, in addition to ochratoxin $A$, the mycotoxin fumonisin $B_{2}\left(\mathrm{FB}_{2}\right)$ (Frisvad et al. 2007). Then, it has been shown that strains of $A$. niger from coffee beans and raisins produced together with $\mathrm{FB}_{2}$ also $\mathrm{FB}_{4}$ (Noonim et al. 2009; Mogensen et al. 2009). Logrieco et al. (2009) reported some strains of $A$. niger from grape producing $\mathrm{FB}_{2}$ and the occurrence of $\mathrm{FB}_{2}$ in two must samples, and pointed out the potential mycotoxicological risk of grape and derived products colonized by this species. Fumonisins have been extensively studied as mycotoxins with cancer-promoting activity and are associated with a number of animal and human diseases (Marasas 2001). Mogensen et al. (2009) has recently shown that $A$. niger strains isolated from raisins are able to produce both $\mathrm{FB}_{2}$ and $\mathrm{FB}_{4}$ when cultured on either grapes or raisins.

The objective of this study was to investigate the presence of $\mathrm{FB}_{2}$ and $\mathrm{FB}_{4}$ in market wines in order to evaluate the potential risk for wine consumers. 


\section{Materials and methods}

4

Wine samples. Fifty-one bottled samples of red (45), white (5) and rosè (1) wine were randomly purchased from the market in Apulia (Table 1). These wines orignated from most Italian wine producing areas including Veneto (10), Apulia (6), Piedmont (6), Trentino Alto Adige (5), Campania (4), Tuscany (4), Lombardy (3) Emilia Romagna (3), Sardinia (2), Sicily (2), Friuli Venezia Giulia (1), Lazio (1), Umbria (1). The year of production ranged from 2004 to 2008 with most in 2007.

\section{Fumonisins analysis}

Fumonisin $\mathrm{B}_{2}$ standard was purchased from Sigma-Aldrich (Milan, Italy), while fumonisin $\mathrm{B}_{4}$ was kindly offered by Mark Busman (National Center for Agricultural Utilization Research, Peoria, Illinois, USA). Standards were dissolved in methanol at $1 \mathrm{mg} \mathrm{mL} \mathrm{m}^{-1}$ concentration, working solution were prepared using a solution $\mathrm{CH}_{3} \mathrm{OH} / \mathrm{H}_{2} \mathrm{O}(70: 30, v / v)$. In Figure 1 are reported the chemical structures of $\mathrm{FB}_{2}$ and $\mathrm{FB}_{4}$. Fumonisin $\mathrm{B}_{1}$ (SigmaAldrich, Milan, Italy) was also analyzed in the tested wines.

$\mathrm{FB}_{2}$ and $\mathrm{FB}_{4}$ were analysed using $7.5 \mathrm{~mL}$ of wine sample mixed with $2.5 \mathrm{~mL}$ of methanol and stirred for $2 \mathrm{~min}$ at room temperature. The sample was acidified to $\mathrm{pH} 3$ using $1 \mathrm{M}$ hydrochloric acid and then loaded on a reversed phase Strata C18-E $500 \mathrm{mg}$ cartridge (Phenomenex, Torrance, CA, USA), previously conditioned with methanol (5 $\mathrm{mL})$ and water $(5 \mathrm{~mL})$. The column was washed with water $(3 \mathrm{~mL})$, methanol/water $(1: 3,5$ $\mathrm{mL}$ ) and then fumonisins mixture was eluted with $10 \mathrm{~mL}$ methanol. The eluate was dried 
using a centrifuge evaporator (Savant Instruments Inc., Farmingdale, NY, USA), dissolved in $750 \mu \mathrm{L}$ of methanol/water (70:30), ultracentrifuged at $13,400 \mathrm{~g}$ for $3 \mathrm{~min}$ and then the residue was used for LC/MS/MS analyses. Recoveries for the toxins were measured by spiking $7.5 \mathrm{~mL}$ of wine with $\mathrm{FB}_{2}$ and $\mathrm{FB}_{4}$ at three different concentrations $(1 \mathrm{ng} / \mathrm{mL}, 5$ $\mathrm{ng} / \mathrm{mL}$ and $10 \mathrm{ng} / \mathrm{mL}$ ); each experiment was repeated three times on two non consecutive days by different operators. $\mathrm{FB}_{2}$ and $\mathrm{FB}_{4}$ recoveries in spiked samples averaged $83.2 \%$ and $79.4 \%$, respectively. The calibration curve showed good linearity in the range 1-1000 ng/mL. All chromatographic points of calibration curve were run in triplicate and the mean values are reported. The standard deviation was less than $5 \%$.

The detection limit (LOD with a signal to noise ratio of 3) for $\mathrm{FB}_{2}$ was $0.25 \mathrm{ng} / \mathrm{mL}$ while the quantification limit (LOQ with a signal to noise ratio of 9) was $0.5 \mathrm{ng} / \mathrm{mL}$. The detection limit (LOD with a signal to noise ratio of 3 ) for $\mathrm{FB}_{4}$ was $0.7 \mathrm{ng} / \mathrm{mL}$ while the quantification limit (LOQ with a signal to noise ratio of 9) was $1.5 \mathrm{ng} / \mathrm{mL}$.

Chromatographic separation of extracts was performed using an HPLC apparatus equipped with two micropumps Series 200 (Perkin Elmer, Canada Shelton, USA) and a Gemini $5 \mathrm{u} \mathrm{C}_{18} 110 \AA$ column (150 x 2 mm) (Phenomenex, Torrance, CA, USA). The chromatographic solvents were water $0.1 \%$ formic acid (eluent $\mathrm{A}$ ) and $\mathrm{CH}_{3} \mathrm{CN} / \mathrm{MeOH}$ $(80: 20 v / v), 0.1 \%$ formic acid (eluent B). The gradient program was as follow: $30-100 \% \mathrm{~B}$ (8 min), $100 \%$ B (3 min), 100-30\% B (3 min), at a constant flow of $0.2 \mathrm{~mL} / \mathrm{min}$. The injection volume was $20 \mu \mathrm{L}$. MS/MS analyses of $\mathrm{FB}_{2}$ and $\mathrm{FB}_{4}$ were performed on an API 3000 triple quadrupole mass spectrometer (Applied Biosystems, Canada) equipped with a 
1 Declustering Potential (DP) $70 \mathrm{~V}$, focus potential $340 \mathrm{~V}$. Collision energy (CE) $51 \mathrm{~V}$ and $242 \mathrm{~V}$ generated daughter ions 336.2 and $512.2 \mathrm{~m} / \mathrm{z}$, for $\mathrm{FB}_{2}$; whereas for $\mathrm{FB}_{4}$ collision 3 energy (CE) $48 \mathrm{~V}$ and $37 \mathrm{~V}$ generated daughter ions 338.5 and $514.3 \mathrm{~m} / \mathrm{z}$. These mass 4 parameters were optimised by preliminary experiments with a direct infusion of pure 5 compounds $(10 \mu \mathrm{g} / \mathrm{mL})$ at a constant flow rate of $6 \mu \mathrm{L} / \mathrm{min}$ using a model 11 syringe pump 6 (Harvard Apparatus, Holliston, MA, USA) into the mass spectrometer source. Drying gas (air) was heated to $350^{\circ} \mathrm{C}$. Analyses were performed in the positive ion mode in MRM (multiple reaction monitoring), ion mode, $\mathrm{FB}_{2}$ showed an $[\mathrm{M}+\mathrm{H}]^{+}$ion at $m / z, 706.4, \mathrm{FB}_{4}$ $9 \quad$ showed an $[\mathrm{M}+\mathrm{H}]^{+}$ion at $m / z 690.4$.

In Figure 2 is reported the Total Ion Chromatogram (TIC) of a sample of wine artificially contaminated with $1 \mu \mathrm{g} / \mathrm{L}$ of $\mathrm{FB}_{2}$ and $\mathrm{FB}_{4}$ been using to evaluate the 13 identify eventual molecules interfering in the fumonisin analysis.

\section{Results and discussion}

This is the first report relevant to $\mathrm{FB}_{2}$ and $\mathrm{FB}_{4}$ surveillance in wine samples. Shephard et al. (2005) reported fumonisins determination in maize beer in South Africa by reversed-phase HPLC, after $o$-phthaldialdehyde (OPA) post-run derivatization. The analytical method reported in this paper represents a real advance in the field of mycotoxin surveillance in foods by using tandem mass spectrometry techniques. In particular, these minimal changes made to the method of Shephard et al. (2005) allow to reduce the time of the analysis and 
1 the handling of samples of alcoholic beverages at risk of contamination by fumonisins with benefits both on the values of recovery of the analytes and cost analysis.

Frisvad et al. (2007) reported a semiquantitative method for fumonisins analysis on agar using selective ion monitoring electrospray LC-MS with a time-of-flight mass spectrometer. Our work was a quantitative analysis of $\mathrm{FB}_{2}$ and $\mathrm{FB}_{4}$ on wine by liquid chromatography coupled to electrospray ionization tandem mass spectrometry (LC/MS/MS). Acquisition was in positive ion mode, $\mathrm{FB}_{1}$ showed an $[\mathrm{M}+\mathrm{H}]^{+}$ion at $m / z$ 722.4, $\mathrm{FB}_{2}$ showed an $[\mathrm{M}+\mathrm{H}]^{+}$ ion at $m / z, 706.4, \mathrm{FB}_{4}$ showed an $[\mathrm{M}+\mathrm{H}]^{+}$ion at $m / z$ 690.4. CAD (Collision Activated Dissociation) of these protonated molecules produced product ions and the two main daughter peaks were selected to be monitored in the MRM mode. Previous studies on fumonisins analysis by LC/MS/MS (Faberi et al. 2005; Bartók et al. 2006) showed that the most abundant products ion were $m / z, 352.0$ and $m / z, 336.0$, respectively for $\mathrm{FB}_{1}$ and $\mathrm{FB}_{2}$, corresponding to the loss of water and two tricarboxylic acids (TCA) from the alkyl backbone $\left[\mathrm{MH}-2 \mathrm{TCA}-\mathrm{H}_{2} \mathrm{O}\right]^{+}$. In addition to these ions, our MS/MS spectra showed the product ions at $m / z 528.1$ and $m / z \quad 512.2$ corresponding to the loss of water and a tricarboxylic acid $\left[\mathrm{MH}-\mathrm{TCA}-\mathrm{H}_{2} \mathrm{O}\right]^{+}$(Table 1). For $\mathrm{FB}_{4}$ analysis the product ions $\mathrm{m} / z, 514.3$ and 338.5 were monitored, corresponding to $[\mathrm{MH}-\mathrm{TCA}]^{+}$and $[\mathrm{MH}-2 \mathrm{TCA}]^{+}$(Bartók et al. 2006).

Using chromatographic conditions described in this work, fumonisins showed retention times of 3.7, 4.4 and 5.1 min for $\mathrm{FB}_{1}, \mathrm{FB}_{2}$ and $\mathrm{FB}_{4}$, respectively.

The occurrence of $\mathrm{FB}_{2}$ and $\mathrm{FB}_{4}$ was investigated in a total of 51 wine samples collected 


\begin{abstract}
1 molecular ion peaks, peak fragments and chromatographic retention time. The distribution
2 of $\mathrm{FB}_{2}$ in wine is resumed in Table $1 . \mathrm{FB}_{2}$ was detected in 9 samples representing $17.6 \%$ of

3 the whole samples and $\mathrm{FB}_{2}$ concentrations in the positive samples ranged from 0.4 to 2.4

$4 \mathrm{ng} / \mathrm{mL}$. TIC of wine sample \#43 positive for $\mathrm{FB}_{2}$ is reported in Figure 3. This study shows

5 that there is a real risk of contamination in wine with $\mathrm{FB}_{2}$. No $\mathrm{FB}_{4}$ was detected in the

6 wine samples. Likewise no $\mathrm{FB}_{1}$ was detected, as expected due to the fact that this toxin is

7 not produced by A. niger. Fumonisins, including $\mathrm{FB}_{2}$, have been found in various plants

8 and plant products including corn and corn based products (Marasas 2001), beer (Shephard

9 et al. 2005), black tea leaves (Martins et al. 2001) and asparagus (Logrieco et al. 1998).

10 The regulatory limits in corn and corn based products in USA and Europe are of 2-4 and

$11 \quad 0.2-4 \mu \mathrm{g} / \mathrm{g}$ total fumonisins, respectively (FDA 2001; European Commission 2007).

12 Aspergillus niger represents the major fumonisin producing species among black Aspergilli

13 occurring on grapes (Logrieco et al. 2009) with producing strains accounting for about 75

$14 \%$ of all A. niger strains (Nielsen et al. 2009). This risk is real also considering the consistent

15 presence of $A$. niger on grapes during the growing season, generally higher than that of

16 other black Aspergilli (Leong et al. 2004; Chulze et al. 2006).

17 Wine is also exposed to other mycotoxicological risk due to the natural occurrence of

18 ochratoxin A mainly due to the presence of A. carbonarius in field (Abarca et al. 2001;

19 Battilani et al. 2003). An European report estimated that wine is the second major source of

20 OTA intake in European populations (European Commission, 2002) and a maximum limit

21 for OTA in wine of $2 \mu \mathrm{g} / \mathrm{kg}$ was regulated in the EU (European Commission, 2006).

22 By assuming a daily consumption of $200 \mathrm{~mL}$ wine for a $70 \mathrm{~kg}$ person, i.e. one or two

23 glasses of wine as recommended by the World Health Organization for an healthy response
\end{abstract}


to wine exposure, and assuming a contamination level (approximated per excess) equal to the average of the positive samples of this study, i.e. about $1 \mathrm{ng} / \mathrm{mL} \mathrm{FB}_{2}$, the average exposure to fumonisins through wine consumption would be of about $0.003 \mu \mathrm{g} / \mathrm{kg}$ of body weight (b.w.) per day. Such level of exposure would be far below the guideline provided for risk characterization by the WHO-FAO joint expert committee for food and additives (JECFA) that established the provisory maximum tolerable daily intake (PMTDI) of 2 $\mu \mathrm{g} / \mathrm{kg}$ of body weight to $\mathrm{FB}_{1}, \mathrm{FB}_{2}$ and $\mathrm{FB}_{3}$ alone or in combination. The contribution of wine to mean daily intake of fumonisins can be considered negligible in the case of people drinking wine manufactured in Italy. Wine alone does not supply the diet with an amount of fumonisins corresponding to PMTDI, but combined with possible fumonisins exposure from the maize based staple diet, it could become a cause for concern when climatic conditions are particularly favourable to the development of toxigenic A. niger strains on grape-vines and the consequent transfer of $\mathrm{FB}_{2}$ to wine. Nevertheless, the number of wine samples included in this study was limited and relevant to Italy only. Additional wine samples from other wine producing countries (e.g. Spain, France, Australia, South Africa, etc) should be investigated for their contamination by fumonisins as well as ochratoxin A in order to have a general view of mycotoxicological risk for the grape-wine chain.

Further studies are needed to better define the environmental conditions and other factors influencing the toxin production, as well as the widespread of fumonisins producing Aspergillus, and the fate of fumonisins during the winemaking process. Geographic differences have been shown in Aspergillus and ochratoxin A contamination of grapes and wines, indicating higher incidence and contamination levels in wines and grapes from the 


\begin{abstract}
1 southern regions of Europe and the lower latitude (Visconti et al. 2008). Aspergillus niger,
2 which includes $\mathrm{FB}_{2}$ producing strains, has been frequently isolated from grapes in Europe (Logrieco et al. 2003), Australia (Leong et al. 2004) and South America (Chulze et al.

2006) and show significant differences in the physiology and ecology with respect to $A$. carbonarius, the main responsible for wine contamination by ochratoxin A.

In conclusion, this report provides a new knowledge about the $\mathrm{FB}_{2}$ occurrence in wine that, added to previous data relevant to its occurrence in grapes and musts, provides a clear evidence that $\mathrm{FB}_{2}$ contamination can occur in the grape-wine chain and, under conditions particularly favourable to its formation, could result in a potential risk for human and animal health.
\end{abstract}

\title{
Ackowledgments
}

This work was supported by EC KBBE-2007-222690-2 MYCORED. The authors thank Giuseppe Cozzi for his valuable technical assistance and Mark Busman (NCAUR, Peoria, Illinois, USA) for $\mathrm{FB}_{4}$ standard.

\section{References}

Abarca ML, Accensi F, Bragulat MR, Cabanfies FJ. 2001. Current importance of ochratoxin A-producing Aspergillus spp. Journal of Food Protection 64:903-906.

Bartók T, Szécsi A, Szekeres A, Mesterházy A, Bartók A. 2006. Detection of new fumonisin mycotoxins and fumonisin-like compounds by reversed-phase highperformance liquid chromatography/electrospray ionization ion trap mass spectrometry. Rapid Communication Mass Spectrometry 20:2447-2462. 
Battilani P, Giorni P, Pietri A. 2003. Epidemiology of toxin producing fungi and ochratoxin A occurrence in grape. European Journal of Plant Pathology 109:715-722.

Bellí N, Ramos AJ, Sanchis V, Marín S. 2004. Incubation time and water activity effects on ochratoxin A production by Aspergillus section Nigri strains isolated from grapes. Letters in Applied Microbiology 38:72-77.

Chulze SN, Magnoli CE, Dalcero AM. 2006. Occurrence of ochratoxin A in wine and ochratoxigenic mycoflora in grapes and dried vine fruits in South America. International Journal of Food Microbiology 111:S5-S9.

European Commission. 2002. Report on tasks for scientific cooperation, Task 3.2.7: Assessment of dietary intake of ochratoxin A in the population of EU Member States. SCOOP, Directorate-General Health and Consumer Protection, Brussels, Belgium. http://europa.eu/comm/food/fs/scoop/3.2.7_en.pdf. Accessed 20 Jan 2009.

European Commission. 2006. Commission Regulation (EC) 1881/2006 setting maximum levels for certain contaminants in foodstuffs. Official Journal of the European Union 20.12.2006, L 364:5-24.

European Commission. 2007. Commission Regulation (EC) 1126/2007 setting maximum levels for certain contaminants in foodstuffs as regards Fusarium toxins in maize and maize products. Official Journal of the European Union 22.9.2007, L 255:14-17.

Faberi A, Foglia P, Pastorini E, Samperi R, Lagana`A. 2005. Determination of type B fumonisin mycotoxins in maize and maize-based products by liquid chromatography/tandem mass spectrometry using a QqQlinear ion trap mass spectrometer. Rapid Communications in Mass Spectrometry 19:275-282. 
$1 \quad$ FDA (US Food and Drug Administration). 2001. Guidance for industry: Fumonisin levels 2 in human foods and animal feeds. Federal Register November 9, 2001 (http://www.fda.gov/Food/GuidanceComplianceRegulatoryInformation/GuidanceDocu ments/ChemicalContaminantsandPesticides/ucm109231.htm) Accessed 20 Jan 2009.

Frisvad J C, Smedsgaard J Jørn, Samson R A, Larsen T O, Thrane U. 2007. Fumonisin B 2 production by Aspergillus niger. Journal Agricultural and Food Chemistry 55(23): 9727-9732.

Leong S, Hocking AD, Pitt JI. 2004. Occurrence of fruit rot fungi (Aspergillus Section Nigri) on some drying varieties of irrigated grapes. Australian Journal of Grape and Wine Research 10:83-88.

11 Logrieco A, Doko B, Moretti A, Frisullo S, Visconti A. 1998. Occurrence of fumonisin B1 and B2 in Fusarium proliferatum infected asparagus plants. Journal of Agricultural and Food Chemistry 46:5201-5204.

Logrieco A, Bottalico A, Mulè G, Moretti A, Perrone G. 2003. Epidemiology of toxigenic fungi and their associated mycotoxins for some Mediterranean crops. European Journal of Plant Pathology 109:645-667. Additives and Contaminants Part A, 26:1495-1500.

Marasas WFO. 2001. Discovery and occurrence of the fumonisins. A historical perspective.

Logrieco A, Ferracane R, Haidukowsky M, Cozzi G, Visconti A, Ritieni A. 2009. Fumonisin B2 production by Aspergillus niger from grapes and natural occurrence in must. Food Environmental Health Perspectives 109 (suppl. 2):239-243. 
Martins ML, Martins HM, Bernardo F. 2001. Fumonisin B1 and B2 in black tea and medicinal plants. Journal of Food Protection 64:1268-1270.

Mogensen JM, Frisvad JC, Thrane U, Nielsen KF. 2009. Production of fumonisin $B_{2}$ and $B_{4}$

by Aspergillus niger on grapes and raisins. Journal of Agricultural and Food Chemistry, DOI: $10.1021 /$ jf903116q

Nielsen K F, Mogensen JM, Johansen M, Larsen TO, Frisvad JC. 2009. Review of secondary metabolites and mycotoxins from the Aspergillus niger group. Analytical and Bioanalytical Chemistry 395:1225-1242.

Noonim P, Mahakarnchanakul W, Nielsen KF, Frisvad JC, Samson RA. 2009. Fumonisin B2 production by Aspergillus niger in Thai coffee beans. Food Additives and Contaminants 26:94-100.

Perrone G, Mule' G, Susca A, Battilani P, Pietri A, Logrieco A. 2006. Ochratoxin A production and AFLP analysis of Aspergillus carbonarious, A. tubigensis and A. niger strains isolated from grape in Italy. Applied and Environmental Microbiology 72: 680-685.

Shephard G, van der Westhuizen L, Gatyeni PM, Somdyala NIM, Burger HM, Marasas WFO. 2005. Fumonisin mycotoxins in traditional xhosa maize beer in South Africa. Journal of Agricultural and Food Chemistry 53:9634-9637.

Visconti A, Pascale M, Centonze G. 1999. Determination of ochratoxin A and domestic and imported beers in Italy by immunoaffinity column-linked HPLC. Journal of Chromatography A, 888:321-326. 
1 Visconti A, Perrone G, Cozzi G, Solfrizzo M. 2008. Managing ochratoxin A risk in the grape-wine food chain. Food Additives and Contaminants 25:193-202.

WHO (World Health Organization). 2001. Ochratoxin A. In Safety Evaluation of Certain Mycotoxins in Food; WHO Food Additives Series 47; FAO Food and Nutrition Paper 74; WHO: Geneva, Switzerland, pp. 281-415.

Zimmerli B, Dick R. 1996. Ochratoxin A in Table wine and grape-juice: occurrence and risk assessment. Food Additives and Contaminants 13:655-668. 
1

2

3

4

5

6

7

8

9

104

11

12

13

14

15

16

17

18

19

20

21

22

23

24

25

26

27

28

29

30

31

32

33

34

35

36

37

38

39

40

41

42

43

44

45

46

47

48

49

50

51

52

53

54

55

56

57

58

59

60

15

17

18

19

20

21

22

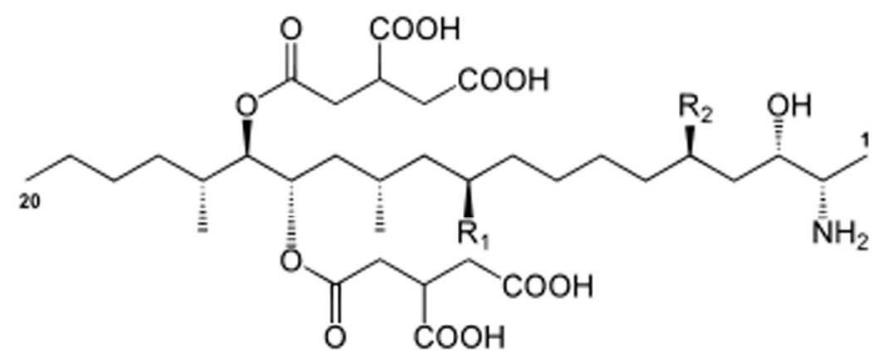

$\mathrm{FB}_{2}: \mathrm{R}_{1}=-\mathrm{H} ; \mathrm{R}_{2}=\mathrm{OH}$

$\mathrm{FB}_{4}: \mathrm{R}_{1}=\mathrm{H} ; \mathbf{R}_{\mathbf{2}}=-\mathrm{H}$

16 Figure 1: Chemical structures of Fumonisins $\mathrm{B}_{2}\left(\mathrm{FB}_{2}\right)$ and $\mathrm{B}_{4}\left(\mathrm{FB}_{4}\right)$ 


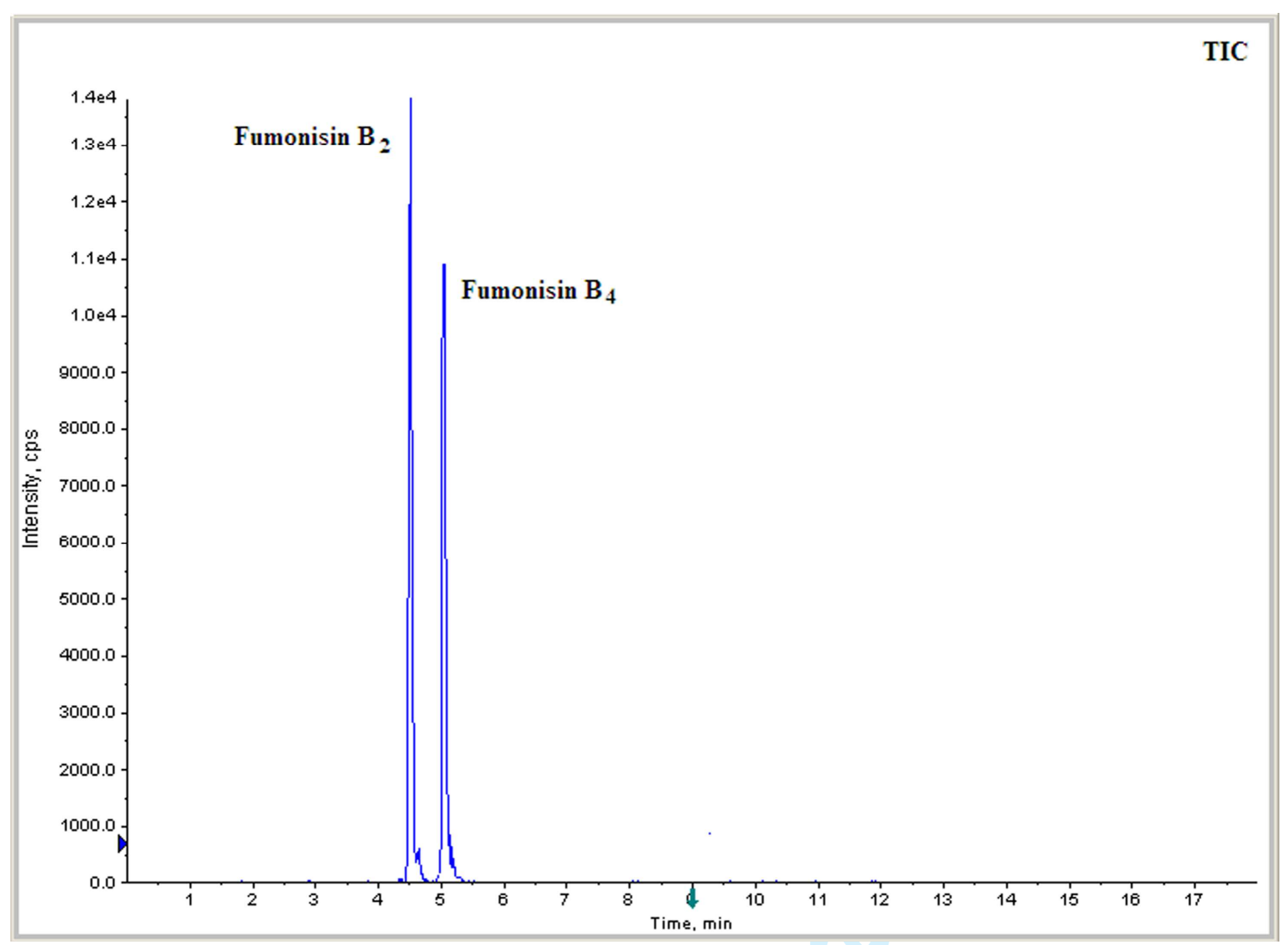

5 Figure 2: Total Ion Chromatogram (TIC) of a blank sample spiked with Fumonisin $\mathrm{B}_{2}$ and 6 Fumonisin $\mathrm{B}_{4}$ standards at $1 \mu \mathrm{g} / \mathrm{L}$ 


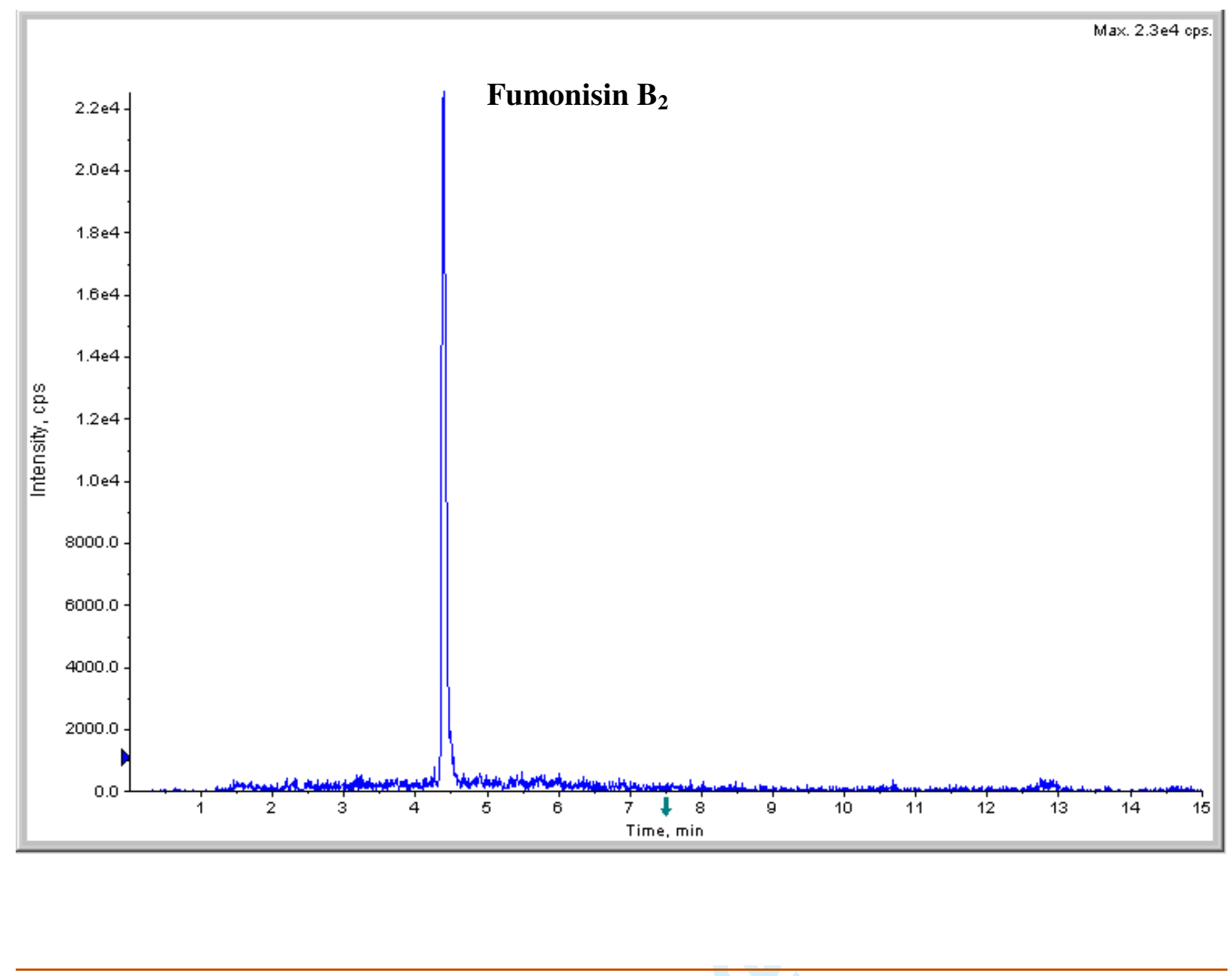

2 Figure 3: Total Ion Chromatogram (TIC) of wine sample \#43 positive for $\mathrm{FB}_{2}$ 
1 Table 1. Distribution of wine samples, with reference to production region and year, and 2 relevant occurrence of Fumonisin $\mathrm{B}_{2}$

\begin{tabular}{|c|c|c|c|c|}
\hline $\mathbf{N}^{\circ}$ & Origin & Wine & Year & $\begin{array}{c}\mathbf{F B}_{2} \\
(\mathrm{ng} / \mathrm{mL})\end{array}$ \\
\hline 1 & Apulia & Red & 2005 & n.d.* \\
\hline 2 & Apulia & Red & 2007 & n.d. \\
\hline 3 & Apulia & Red & 2007 & 0.6 \\
\hline 4 & Apulia & Red & 2007 & 0.8 \\
\hline 5 & Apulia & Red & 2006 & n.d. \\
\hline 6 & Apulia & Red & 2005 & n.d. \\
\hline 7 & Veneto & Red & 2007 & n.d. \\
\hline 8 & Veneto & Red & 2007 & n.d. \\
\hline 9 & Veneto & Red & 2007 & n.d. \\
\hline 10 & Veneto & Red & 2006 & n.d. \\
\hline 11 & Veneto & Red & 2007 & n.d. \\
\hline 12 & Veneto & Red & 2007 & 1.2 \\
\hline 13 & Veneto & Red & 2006 & n.d. \\
\hline 14 & Veneto & Red & 2005 & n.d. \\
\hline 15 & Veneto & Red & 2007 & n.d. \\
\hline 16 & Veneto & Red & 2006 & n.d. \\
\hline 17 & Piemonte & Red & 2006 & 1.1 \\
\hline 18 & Piedmont & Red & 2007 & n.d. \\
\hline 19 & Piedmont & Red & 2007 & n.d. \\
\hline 20 & Piedmont & Red & 2007 & n.d. \\
\hline 21 & Piedmont & Red & 2007 & n.d. \\
\hline 22 & Piedmont & Red & 2008 & 0.5 \\
\hline 23 & Trentino Alto Adige & Red & 2007 & n.d. \\
\hline 24 & Trentino Alto Adige & Red & 2007 & n.d. \\
\hline 25 & Trentino Alto Adige & Red & 2007 & n.d. \\
\hline 26 & Trentino Alto Adige & Red & 2007 & n.d. \\
\hline 27 & Trentino Alto Adige & White & 2006 & n.d. \\
\hline 28 & Tuscany & Red & 2004 & 0.5 \\
\hline 29 & Tuscany & Red & 2004 & 0.7 \\
\hline 30 & Tuscany & Red & 2006 & n.d. \\
\hline 31 & Tuscany & Red & 2007 & n.d. \\
\hline 32 & Lombardy & Red & 2006 & n.d. \\
\hline 33 & Lombardy & Red & 2007 & n.d. \\
\hline 34 & Lombardy & Red & 2007 & n.d. \\
\hline 35 & Basilicata & Red & 2007 & n.d. \\
\hline
\end{tabular}




\begin{tabular}{|l|l|l|l|l|}
\hline 36 & Emilia Romagna & Red & 2007 & n.d. \\
\hline 37 & Emilia Romagna & Red & 2007 & n.d. \\
\hline 38 & Emilia Romagna & Red & 2007 & 0.6 \\
\hline 39 & Friuli Venezia Giulia & Red & 2007 & n.d. \\
\hline 40 & Abruzzi & Red & 2007 & n.d. \\
\hline 41 & Marche & Red & 2007 & n.d. \\
\hline 42 & Sardinia & Red & 2007 & n.d. \\
\hline 43 & Sardinia & Red & 2006 & 2.4 \\
\hline 44 & Campania & Red & 2006 & n.d. \\
\hline 45 & Campania & Red & 2007 & n.d. \\
\hline 46 & Campania & Rosè & 2006 & n.d. \\
\hline 47 & Campania & White & 2007 & n.d. \\
\hline 48 & Sicily & Red & 2007 & n.d. \\
\hline 49 & Sicily & White & 2007 & n.d. \\
\hline 50 & Lazio & White & 2007 & n.d. \\
\hline 51 & Umbria & White & 2007 & n.d. \\
\hline
\end{tabular}

$*$ n.d. $=$ not detected $(<0.3 \mathrm{ng} / \mathrm{mL})$ 